\title{
Growth and growth factors in diabetes mellitus
}

\author{
S SALARDI, S TONIOLI, P TASSONI, M TELLARINI, L MAZZANTI, AND E CACCIARI \\ 2nd Paediatric Clinic of the University, University of Bologna, Bologna, Italy
}

SUMmARY Growth of 79 children with diabetes was analysed at diagnosis and again after one to 10.7 years of treatment with insulin. Both sexes were tall at onset, whereas at the last observation boys alone showed significant growth retardation. Height standard deviation score (SDS), however, showed no significant fall either in 32 subjects reassessed after five years of disease or in 18 subjects examined at full stature. Skeletal maturity was not significantly impaired after treatment. Pubertal growth spurt was reduced, especially in girls and in subjects with onset of disease at or around puberty. We found no significant correlation between height and height velocity SDS and glycosylated haemoglobin values or secretion of growth hormone during the arginine test. Somatomedin C values were correlated with height velocity SDS in prepubertal boys. The results of this study suggest that there are interferences in the growth of children with diabetes but that they do not seem to have a significant influence on adult height.

It is well recognised that growth is seriously impaired in cases of very poorly controlled diabetes. ${ }^{1}$ What is less certain, however, is whether diabetes influences growth or limits adult height in children treated conventionally in whom the disease is fairly well controlled-that is, most cases today.

There are some discrepancies in the findings of various authors who have published papers on this subject. Tattersall et al found that in patients with type 1 diabetes there was a decrease in adult height compared with their identical non-affected twins. ${ }^{2}$ Growth delay was also observed by Jivani $e t a l^{3}$ and Edelsten et al, ${ }^{4}$ while according to Birkbeck, ${ }^{5}$ Rudolf $e t a l,{ }^{6}$ and $\mathrm{Jackson}^{7}$ children with a fairly high degree of metabolic control showed normal growth rate.

The methods used in these studies vary, however, and are questionable as regards the way in which growth delay was calculated, the type of follow up used, and the methods used for assessing diabetes control.

This study reports our experience with a group of children with diabetes followed longitudinally from the onset of disease. In these subjects height and height velocity were evaluated as standard deviation scores (SDS) and control of the disease as total glycosylated haemoglobin $\left(\mathrm{HbA}_{1 \mathrm{C}}\right)$.

Further, in these subjects growth rate was compared with secretion of growth hormone and plasma somatomedin $\mathrm{C}$ concentrations.

\section{Patients}

Seventy nine subjects ( 35 boys and 44 girls, with 58 prepubertal and 21 pubertal) with type 1 diabetes mellitus, aged $0 \cdot 7-14.8$ years (mean (SD) $7 \cdot 44$ (3.56) years) were examined at the onset of disease. These subjects were observed over a period of one to 10.7 years (mean (SD) 4.48 (2.59) years); 32 (18 girls and 14 boys) have been followed longitudinally for at least five years.

At the onset of disease and at each subsequent control (three or four times a year) the following details were evaluated in each child: height as centile and as SDS, pubertal stage, bone age (in 66 cases), and control of the disease by $\mathrm{HbA}_{1 \mathrm{C}}$ assay. During this entire period of observation mean (SD) $\mathrm{HbA}_{1 \mathrm{C}}$ was $11.17(1.31) \%$ for boys and 11.96 $(1 \cdot 81) \%$ for girls. We considered subjects with $\mathrm{HbA}_{1 \mathrm{C}}$ values $<10 \%$ as having good control, those with $\mathrm{HbA}_{1 \mathrm{C}}$ values between 10 and $12 \%$ as having fair control, and those with values $>12 \%$ as having poor control.

Height velocity was calculated annually as SDS. Somatomedin $\mathrm{C}$ basal values were determined in 43 subjects, and 72 also had an arginine test to evaluate growth hormone. Overall secretion of growth hormone was evaluated as the integrated area of the curve.

During the observation period, 26 subjects (nine boys and 17 girls) entered puberty, while 18 subjects (10 boys and eight girls) reached adult height.

\section{Methods}

Tanner's centiles ${ }^{8}$ were used in the evaluation of height and height velocity. 
Height and height velocity SDS were calculated according to the formula $\frac{\mathrm{Xi}-\mathrm{Mx}}{\mathrm{Sx}}$, where $\mathrm{Xi}$ is the actual measurement, $\mathrm{Mx}$ is the mean (50th centile) of subjects of the same chronological age, and Sx is the standard deviation corresponding to that age. In those cases where bone age was delayed or advanced by more than one standard deviation compared with chronological age SDS referred to bone age.

Pubertal stage was evaluated according to Tanner ${ }^{9}$ and bone age according to Greulich and Pyle's atlas. ${ }^{10}$

$\mathrm{HbA}_{1 \mathrm{C}}$ was assayed with Trivelli's method (BIORAD Column Method) ${ }^{11}$ and growth hormone by radioimmunoassay. Somatomedin $\mathrm{C}$ was measured by radioimmunoassay (RIA kit; Nicholas Institute Products, San Juan Capistrano, California, United States) in accordance with the method of
Furlanetto et al. ${ }^{12}$ The intra- and interassay variabilities were $5 \%$ and $10 \%$, respectively. The ' $r$ ' correlation coefficient, Student's $t$ test, paired $t$ test, and $\chi^{2}$ test were used for statistical analysis of the data.

\section{Results}

Height. Figures 1 and 2 and Table 1 show the height distribution of all the subjects, both at onset of disease and at the last observation. From Table 1, it is evident that at the onset of disease most of the boys and girls were tall and that the number of boys whose height was over the 50th centile was significantly $(\mathrm{p}<0.05)$ greater at the onset of disease than after treatment.

Table 2 shows the mean centiles and height SDSs both at the onset of disease and at the last observation. Height SDS in the boys was significantly $(p<0.0025)$ higher at the onset of disease than after treatment.

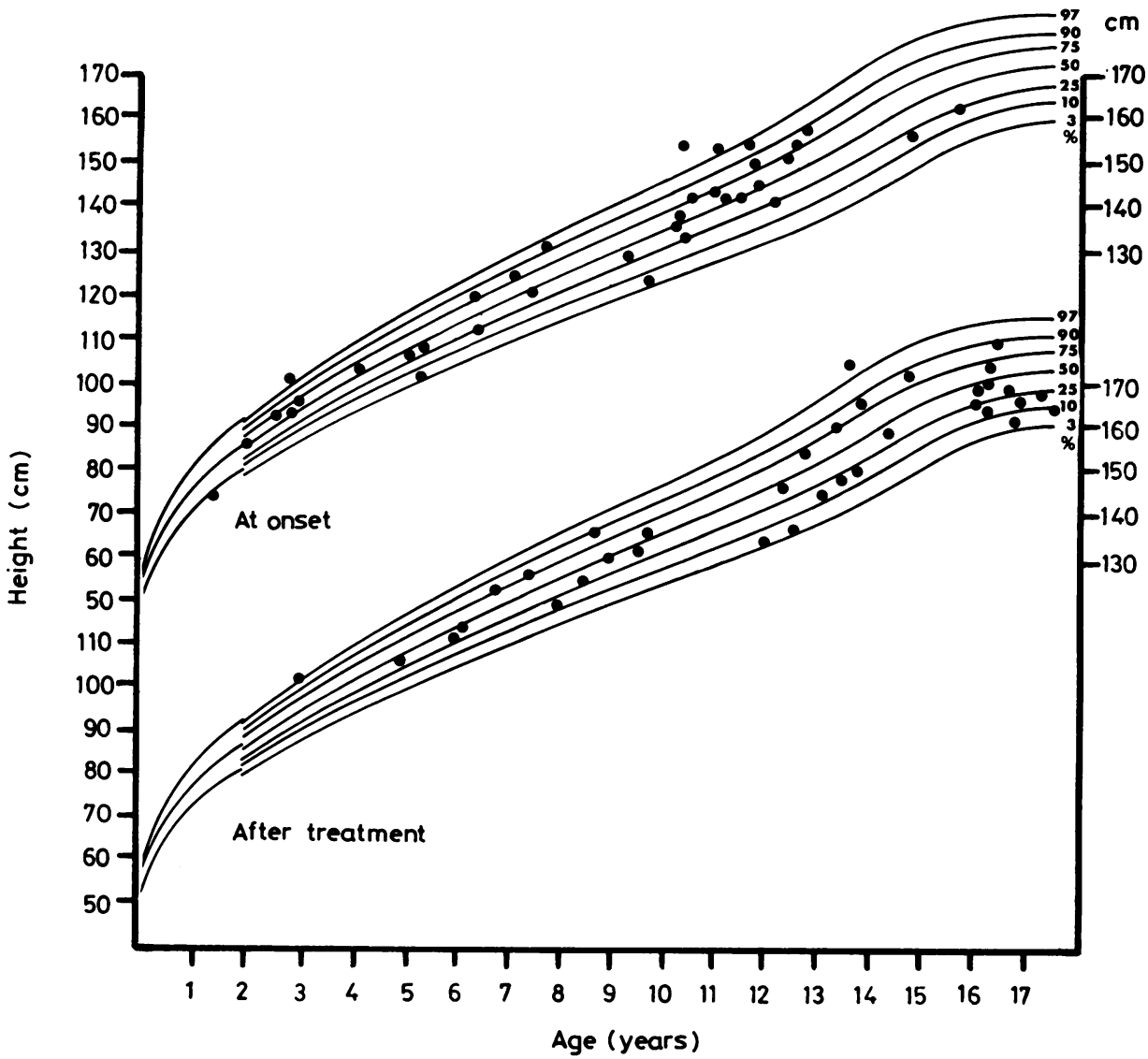

Fig. 1 Height at onset of disease and after treatment in 35 boys with insulin dependent diabetes mellitus. 


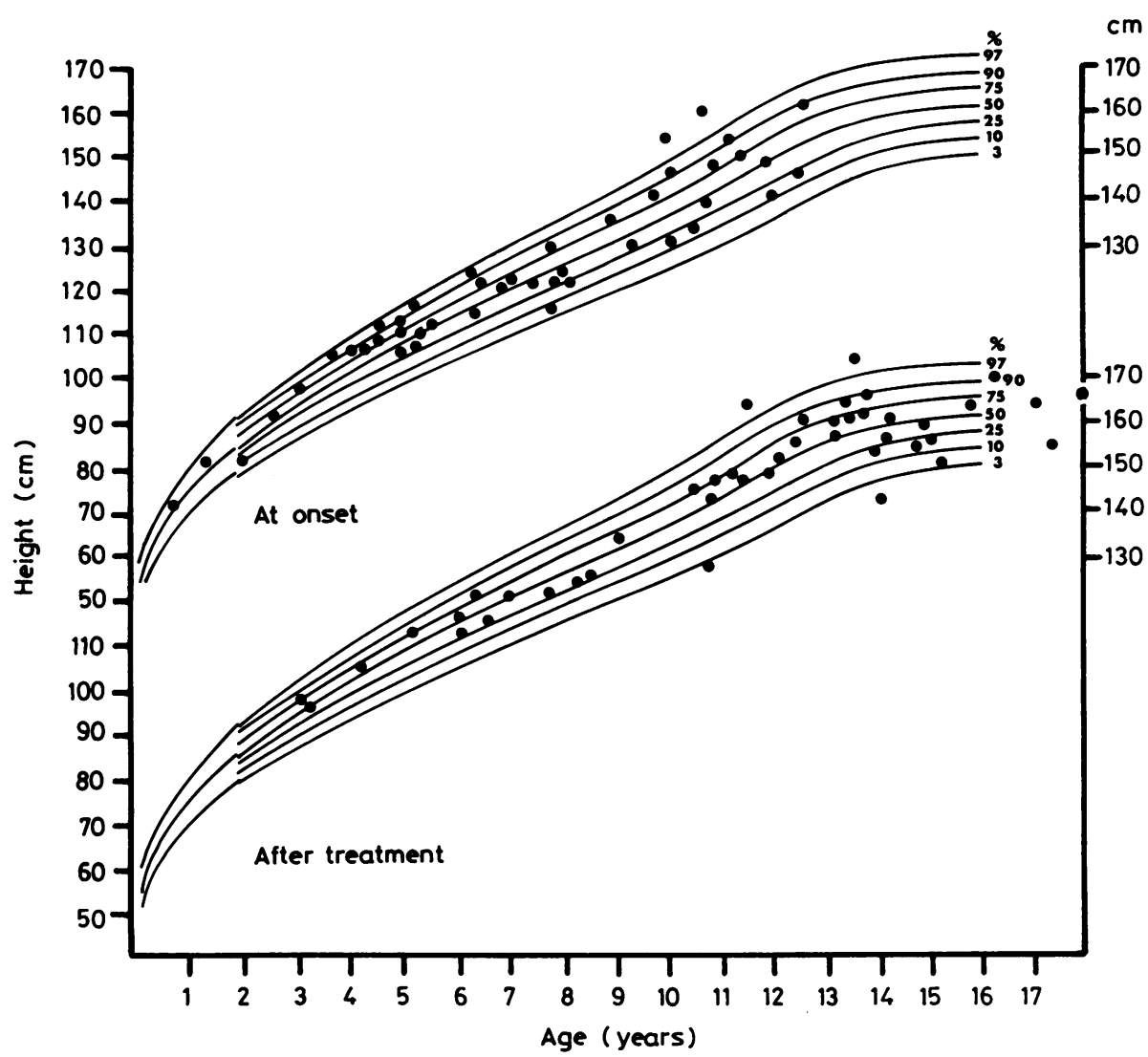

Fig. 2 Height at onset of disease and after treatment for 44 girls with insulin dependent diabetes mellitus.

As the period of treatment in these subjects varied considerably we subsequently made this variable uniform, taking into consideration only those patients ( 32 cases, 14 boys and 18 girls) observed during their first five years of disease. The data referring to these subjects are reported in Table 3. Analysis of these data (paired $t$ test) indicated no differences between SDS values at the onset and in the fifth year of disease.

Table 1 Height at onset and after treatment in children with insulin dependent diabetes mellitus

\begin{tabular}{lll}
\hline & \multicolumn{2}{l}{ No of cases } \\
\cline { 2 - 3 } & $\geqslant 50$ th centile & $<50$ th centile \\
\hline $\begin{array}{l}\text { Boys }(n=35): \\
\text { At onset } \\
\text { After treatment }\end{array}$ & 21 & 14 \\
$\begin{array}{l}\text { Girls }(n=44): \\
\text { At onset } \\
\text { After treatment }\end{array}$ & $12^{*}$ & 23 \\
\hline
\end{tabular}

${ }^{*} \chi^{2}=4 \cdot 64, p<0 \cdot 05$.
Table 2 Mean (SD) height centile value and height standard deviation score (SDS) at onset and after treatment in 35 boys $(M)$ and 44 girls $(F)$ with insulin dependent diabetes mellitus

\begin{tabular}{llll}
\hline & Sex & At onset & After treatment \\
\hline Height centile value & M & $53 \cdot 63(26 \cdot 60)$ & $45 \cdot 48(29.45)$ \\
Height SDS & F & $57.93(27.36)$ & $54.72(27.79)$ \\
& M & $+0.46(1.32)$ & $-0.40(0.99)^{*}$ \\
& F & $+0.49(1.30)$ & $+0.002(1.03)$ \\
\hline
\end{tabular}

${ }^{*} \mathrm{p}<0.0025 v$ Height SDS at onset.

Table 3 Mean (SD) height centile value and height standard deviation score (SDS) at onset and after five years of treatment in 14 boys $(M)$ and 18 girls $(F)$ with insulin dependent diabetes mellitus

\begin{tabular}{llll}
\hline & Sex & At onset & $\begin{array}{l}\text { After five years of } \\
\text { treatment }\end{array}$ \\
\hline Height centile value & $\mathrm{M}$ & $49 \cdot 06(25 \cdot 82)$ & $31 \cdot 20(24 \cdot 67)$ \\
Height SDS & $\mathrm{F}$ & $63 \cdot 10(23 \cdot 92)$ & $57 \cdot 14(25 \cdot 62)$ \\
& $\mathrm{M}$ & $+0.66(1 \cdot 66)$ & $-0 \cdot 37(1.32)$ \\
& $\mathrm{F}$ & $+0.86(1 \cdot 05)$ & $+0 \cdot 052(1 \cdot 05)$ \\
\hline
\end{tabular}


Examination of those subjects who reached full stature during follow up (10 boys and eight girls) showed that the initial mean of the SDS values was not significantly different from the final mean for either boys or girls (Table 4).

Skeletal maturity. The bone age mean, both at the onset of disease and after treatment, did not differ from the chronological age mean (Table 5).

The percentage of subjects with bone age delayed or advanced more than one standard deviation was not significantly different either before or after treatment.

Height velocity. The mean velocity SDS decreased progressively during the first years of disease only in those subjects who were pubertal from onset.

Patients with onset at least three years before

Table 4 Mean (SD) height standard deviation score at onset and at full stature in 18 patients with diabetes

\begin{tabular}{lll}
\hline & At onset & At full stature \\
\hline Boys $(n=10)$ & $+(0 \cdot 10(0 \cdot 60)$ & $-(0 \cdot 50(0 \cdot 90)$ \\
Girls $(\mathrm{n}=8)$ & $+(0 \cdot 11(1 \cdot 64)$ & $+(0 \cdot 03(1 \cdot 63)$ \\
\hline
\end{tabular}

Table 5 Skeletal maturity at onset and after treatment in 30 boys $(M)$ and 36 girls $(F)$ with diabetes

\begin{tabular}{llll}
\hline & Sex & At onset & After treatment \\
\hline Mean (SD) chronological age & $\mathrm{M}$ & $8 \cdot 05(4 \cdot 04)$ & $12 \cdot 34(4 \cdot 14)$ \\
$\quad$ (yrs) & $\mathrm{F}$ & $7 \cdot 23(2 \cdot 94)$ & $11 \cdot 76(3 \cdot 59)$ \\
Mean (SD) bone age (yrs) & $\mathrm{M}$ & $7 \cdot 75(4 \cdot 68)$ & $12 \cdot(0)(4 \cdot 50)$ \\
& $\mathrm{F}$ & $7 \cdot 66(3 \cdot 38)$ & $12 \cdot 14(3 \cdot 41)$ \\
$\%$ Cases with advanced & $\mathrm{M}$ & $10 \cdot 0$ & $10 \cdot 7$ \\
skeletal maturation & $\mathrm{F}$ & $16 \cdot 6$ & $18 \cdot 7$ \\
$\%$ Cases with delayed & $\mathrm{M}$ & $20 \cdot 0$ & $21 \cdot 4$ \\
skeletal maturation & $\mathrm{F}$ & $8 \cdot 4$ & $3 \cdot 1$ \\
\% Cases with normal & $\mathrm{M}$ & $70 \cdot 0$ & $67 \cdot 9$ \\
skeletal maturation & $\mathrm{F}$ & $75 \cdot 0$ & $78 \cdot 2$ \\
\hline
\end{tabular}

puberty showed a growth spurt that was slightly lower than the mean and not delayed. This was especially so in the girls (Fig. 3). On the contrary in those patients with onset at or around puberty the spurt, which had already begun, seemed to be interrupted suddenly (Fig. 4).

Puberty. The data referring to puberty are summarised in Table 6.

Metabolic control. We found no significant correlation between mean $\mathrm{HbA}_{1 \mathrm{C}}$ values obtained over the entire observation period and either height SDS score, values of the difference in the scores before and after treatment, or velocity SDS.

If mean $\mathrm{HbA}_{1 \mathrm{C}}$ values are evaluated by year of disease a significant positive correlation $(p<0.01)$ is found only in the second year of disease between $\mathrm{HbA}_{1 \mathrm{C}}$ values and velocity SDS. The height and height velocity SDS means were no different in subjects with good, fair, or poor control.

Growth hormone and somatomedin C. Somatomedin $\mathrm{C}$ values and secretion of growth hormone during the arginine test did not seem to be significantly correlated either with height SDS, velocity $\mathrm{SDS}$, or $\mathrm{HbA}_{\mathrm{IC}}$ values. Somatomedin $\mathrm{C}$ values were, however, positively correlated with velocity SDS $(p<0 \cdot 05)$ only in prepubertal boys.

As reported in one of our previous papers ${ }^{13}$ it was only in prepubertal subjects that means somatomedin $C$ values seemed to be significantly lower than in the respective control children.

Using the 274 control subjects examined in our previous study, ${ }^{14}$ we subdivided our subjects according to whether somatomedin $C$ values were lower, greater, or within one standard deviation of the mean of subjects of the same sex and pubertal stage.

In boys, both pubertal and prepubertal, height

Table 6 Pubertal development in girls and boys with insulin dependent diabetes mellitus. Values are mean (SD) (range)

\begin{tabular}{|c|c|c|c|c|c|}
\hline \multirow[b]{2}{*}{ Onset of puberty (yrs) } & \multicolumn{2}{|l|}{ Boys } & \multicolumn{3}{|l|}{ Girls } \\
\hline & $\begin{array}{l}11 \cdot 33(1 \cdot 18) \\
(9 \cdot 5()-14)\end{array}$ & $(n=20)$ & $\begin{array}{l}10 \cdot 92(1 \cdot 13) \\
(9-13 \cdot 91)\end{array}$ & & $(n=24)$ \\
\hline Age at menarche (yrs) & - & & $\begin{array}{l}12 \cdot 93(1 \cdot 18) \\
(10 \cdot 25-15 \cdot 16)\end{array}$ & & $(n=20)$ \\
\hline Full stature age (yrs) & $\begin{array}{l}17 \cdot 73(2 \cdot 1) \\
(15 \cdot 16-21 \cdot 83)\end{array}$ & $(n=14)$ & $\begin{array}{l}16 \cdot 00(1 \cdot 89) \\
(13 \cdot 25-19 \cdot 58)\end{array}$ & & $(n=15)$ \\
\hline $\begin{array}{l}\text { Growth rate from onset of } \\
\text { puberty to full stature }(\mathrm{cm})\end{array}$ & $\begin{array}{l}28 \cdot 07(6 \cdot 4) \\
(20 \cdot 45-39)\end{array}$ & $(n=7)$ & $\begin{array}{l}14.91(3.93) \\
(8 \cdot 86-21 \cdot 64) \\
\mathrm{B}_{2} \rightarrow \text { menarche }\end{array}$ & $\begin{array}{l}10 \cdot 80(4 \cdot 62) \\
(4 \cdot 21-21 \cdot 23)\end{array}$ & $\begin{array}{l}(n=13) \\
(n=18)\end{array}$ \\
\hline & & & $\begin{array}{r}\text { Menarche } \rightarrow \text { full } \\
\text { stature }\end{array}$ & $\begin{array}{l}4 \cdot 16(2 \cdot 67) \\
(1 \cdot 32-10 \cdot 54)\end{array}$ & \\
\hline Duration of puberty (yrs) & $\begin{array}{l}6 \cdot 58(1.66) \\
(4.75-8.83)\end{array}$ & $(n=7)$ & $\begin{array}{l}4 \cdot 57(1 \cdot 82) \\
(2 \cdot 52-6 \cdot 42)\end{array}$ & & $(n=13)$ \\
\hline
\end{tabular}




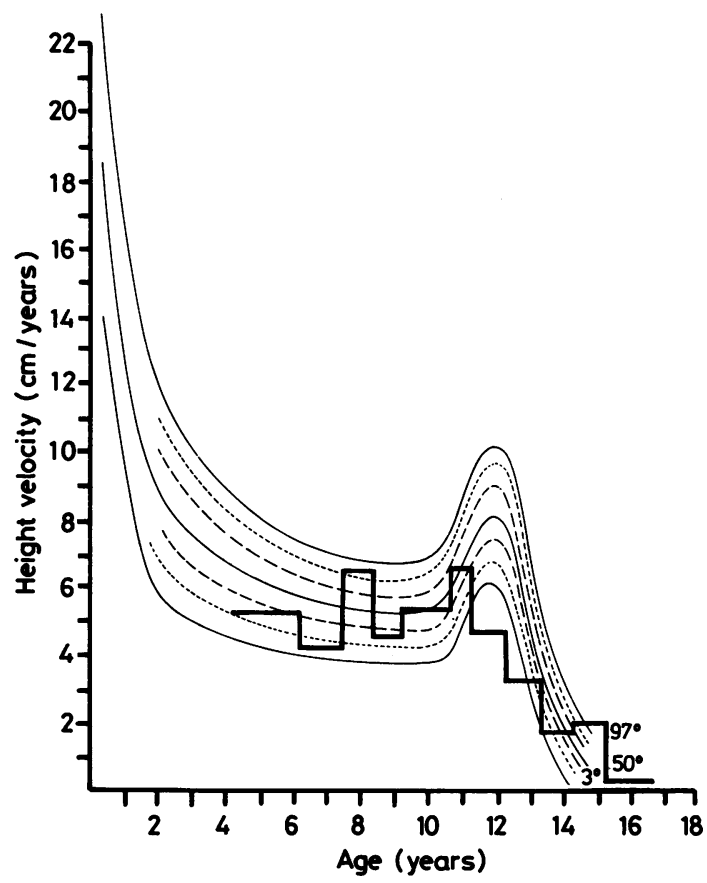

Fig. 3 Height velocity mean in 12 girls with onset of disease at least three years before puberty.

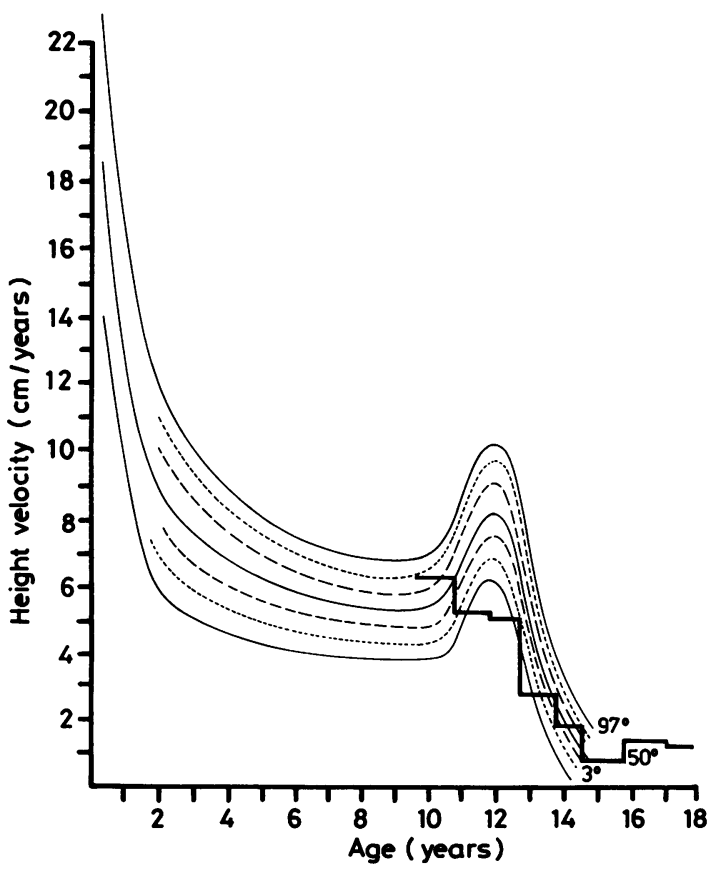

Fig. 4 Height velocity mean in 13 girls with onset of disease at or around puberty. and height velocity SDS were higher in subjects whose somatomedin values were greater by one standard deviation than in those subjects whose somatomedin $\mathrm{C}$ values were lower or within one standard deviation.

\section{Discussion}

The patients with diabetes in this study were taller than average at the onset of disease. This confirms the data reported by Edelsten et al. ${ }^{4}$

Like these authors, we too used the population charts of Tanner and Whitehouse for height as no standards are available for the height of children in our area. Our preliminary data, however, suggest that the height of our healthy children does not differ greatly from that observed by Tanner and his colleagues. It has been hypothesised that the advanced growth of children with diabetes at the onset of disease might be the result of the anabolic activity of insulin, which may exist in abnormal quantities for some time before the clinical onset of diabetes. ${ }^{34}$

Our results concerning height after treatment, however, cannot be interpreted so easily. If, like many authors, ${ }^{3-5}$ we use a cross sectional methodthat is, examining all subjects at their most recent measurement, independently of duration of disease-we find that there is an excess of boys shorter than the mean. If, however, we use a longitudinal method and take account of adult height, although the number of subjects may be small, the differences encountered with the cross sectional method are no longer found.

Given the importance of puberty in determining adult height, we followed other authors ${ }^{3}$ and examined the growth of children with diabetes during this period. According to Jivani et al growth rate is normal until puberty, which is exactly when it is impaired. ${ }^{3}$ These authors state that the pubertal growth spurt is reduced and also delayed among girls only when the onset of disease is well before puberty. This does not agree with our data, but the discrepancy is not easy to interpret as Jivani et al gave no numerical data in their paper. Our patients had a pubertal spurt that was never delayed but was reduced. This occurred more in girls than in boys and also in those with onset of disease around puberty rather than in those with onset well before puberty (Figs. 3 and 4).

Furthermore, we have been unable to indicate any relation between metabolic control and growth data. Paradoxically, as reported by Jivani et al, ${ }^{3}$ the more poorly controlled our patients were at the second year of disease the better they seemed to grow. 
Other studies, however, have come to the opposite conclusion. ${ }^{6}$ Rudolf et al found that growth rate, which was already normal, had doubled in nine adolescents with diabetes receiving intensive treatment (insulin pump or multiple injection) for six months and whose metabolic profile had shown a pronounced improvement. ${ }^{6}$

As regards the time when pubertal development begins and ends, we used the data published by Pezzini $e t$ al $^{15}$ as we have none of our own referring to the healthy population. These authors state that healthy girls begin pubertal development at $10.60 \pm 0.84$ years and have the menarche at $12 \cdot 50 \pm 0.80$ years. Our data indicate that girls with diabetes are about six months behind these averages, while the data of Pezzini et al indicate a delay of one year. ${ }^{15}$

That there were no significant delays in sexual maturity was also suggested by our data concerning skeletal maturity, which, during treatment, followed the physiological pattern. Birkbeck reached the same conclusions concerning skeletal maturity, ${ }^{5}$ while Edelsten et al reported advanced skeletal maturity at onset of disease and a clear decrease in skeletal maturity SDS after treatment only in boys. ${ }^{4}$

Finally, growth hormone concentrations do not seem to interfere with growth or to be influenced by metabolic control. It is worth remembering, however, that these data refer to a precise moment in the history of the disease and therefore, given the extreme variability of secretion of growth hormone in the same subject, it cannot be ruled out that these data might have been different at another time.

Somatomedin C seems to behave differently in the two sexes. While it seems to have no relation to growth characteristics in girls, in boys the relation seems to be very definite. In boys, in fact, the higher the somatomedin $\mathrm{C}$ values the better the growth rate. Further, in prepubertal boys there is a significant correlation between somatomedin $\mathrm{C}$ concentrations and velocity SDS.

We conclude that there seem to be interferences in the growth rate of children and adolescents with diabetes and that they are evident in particular as a decrease in pubertal spurt independent of metabolic control and conditioned, in boys, by production of somatomedin C. These interferences do not seem to have a significant influence on adult height.

The work was supported in part by the Consiglio Nazionale delle Richerche (85.00477.56).

\section{References}

1 Gucst CM. The Mauriac syndrome: dwarfism, hepatomegaly, and obesity with juvenile diabetes mellitus. Diabetes 1953:2:415-7.

2 Tattersall RB, Pyke DA. Growth in diabetic children: studies in identical twins. Lancet 1973;ii:1105-9.

3 Jivani SKM, Rayner PHW. Does control influence the growth of diabetic children? Arch Dis Child 1973:48:109-15.

${ }^{4}$ Edelsten AD, Hughes IA, Oakes S, Gordon IRS, Savage DCL. Height and skeletal maturity in children with newly-diagnosed juvenile-onset diabetes. Arch Dis Child 1981;56:40-4.

5 Birkbeck JA. Growth in juvenile diabetes mellitus. Diabetologia 1972;8:221-4.

${ }^{6}$ Rudolf MCJ, Sherwin RS, Markowitz R, et al. Effect of intensive insulin treatment on linear growth in the young diabetic patient. J Pediatr 1982;101:333-9.

7 Jackson RL. Growth and maturation of children with insulindependent diabetes mellitus. Pediatr Clin North Am 1984:31:545-67.

` Tanner JM. Whitehouse RH, Takaishi M. Standards from birth to maturity for height, weight, height velocity, and weight velocity: British children 1965. Parts I and II. Arch Dis Child 1966;41:454-71; 613-35.

9 Tanner JM. Growth at adolescence. 2nd ed. Oxford: Blackwell Scientific Publications, 1962.

1" Greulich W, Pyle SI. Radiographic atlas of skeletal development of the hand and wrist. 2nd ed. California: Stanford University Press, 1959.

1 Trivelli LA. Ramney HM. Lai HT. Hemoglobin components in patients with diabetes mellitus. $N$ Engl J Med 1971;284:353-7.

12 Furlanetto RW. Pitfalls in the somatomedin-C radioimmunoassay. J Clin Endocrinol Metab 1982:54:1084-6.

13 Salardi S, Cacciari E, Ballardini D, et al. Relationships between growth factors (somatomedin-C and growth hormone) and body development, metabolic control, retinal changes in children and adolescents with IDDM. Diabetes 1986;35:832-6.

14 Cacciari E. Cicognani A, Pirazzoli P, et al. Differences in somatomedin-C between short-normal subjects and those of normal height. J Pediatr 1985;106:891-4.

15 Pezzini MB. Busatta E. Conterno P. Pinelli L. Studio dello sviluppo puberale e del ciclo mestruale. Confronto fra adolescenti affette da diabete tipo 1 ed adolescenti sane. Minerva Ginecol 1983;35:161-73.

Correspondence to Professor E Cacciari, Clinica Pediatrica $2^{\wedge}$ dell' Università, Via Massarenti, 11-40138 Bologna, Italy.

Received 14 July 1986 